\title{
Evolutionary radiations in the species-rich mountain genus Saxifraga L.
}

\author{
J. Ebersbach ${ }^{1 *}\left(\mathbb{D}\right.$, J. Schnitzler $^{1}$, A. Favre ${ }^{1}$ and A.N. Muellner-Riehl ${ }^{1,2}$
}

\begin{abstract}
Background: A large number of taxa have undergone evolutionary radiations in mountainous areas, rendering alpine systems particularly suitable to study the extrinsic and intrinsic factors that have shaped diversification patterns in plants. The species-rich genus Saxifraga L. is widely distributed throughout the Northern Hemisphere, with high species numbers in the regions adjacent to the Qinghai-Tibet Plateau (QTP) in particular the Hengduan Mountains and the Himalayas. Using a dataset of 297 taxa (representing at least $60 \%$ of extant Saxifraga species), we explored the variation of infrageneric diversification rates. In addition, we used state-dependent speciation and extinction models to test the effects of geographic distribution in the Hengduan Mountains and the entire QTP region as well as of two morphological traits (cushion habit and specialized lime-secreting glands, so-called hydathodes) on the diversification of this genus.

Results: We detected two to three rate shifts across the Saxifraga phylogeny and two of these shifts led to radiations within two large subclades of Saxifraga, sect. Ciliatae Haworth subsect. Hirculoideae Engl. \& Irmsch. and sect. Porphyrion Tausch subsect. Kabschia Engl. GEOSSE analyses showed that presence in the Hengduan Mountains had a positive effect on diversification across Saxifraga. Influence of these mountains was strongest in Saxifraga sect. Ciliatae subsect. Hirculoideae given its pronounced distribution there, and thus the radiation in this group can be classified at least partially as geographic. In contrast, the evolution of the cushion life form and lime-secreting hydathodes had positive effects on diversification only in selected Saxifraga sections, including sect. Porphyrion subsect. Kabschia. We therefore argue that radiation in this group was likely adaptive.

Conclusions: Our study underlines the complexity of processes and factors underpinning plant radiations: Even in closely related lineages occupying the same life zone, shifts in diversification are not necessarily governed by similar factors. In conclusion, alpine plant radiations result from a complex interaction among geographical settings and/or climatic modifications providing key opportunities for diversification as well as the evolution of key innovations.
\end{abstract}

Keywords: Evolutionary radiations, alpine habitats, Saxifraga, diversification rates, key innovations, Hengduan Mountains

\section{Background}

Evolutionary radiations resulting in exceptionally speciesrich clades are shaping current patterns of biodiversity in the plant kingdom [1, 2]. Large numbers of evolutionary radiations have been recorded in alpine plant groups [3], and references therein, contributing to the high species diversity of vascular plants found in many mountain systems $[4,5]$. In fact, alpine life zones around the world are proportionally more species-rich than expected by the area they

\footnotetext{
* Correspondence: ebersbach.jana@gmail.com

'Department of Molecular Evolution and Plant Systematics \& Herbarium (LZ), Institute of Biology, Leipzig University, Johannisallee 21-23, D-04103 Leipzig, Germany

Full list of author information is available at the end of the article
}

occupy [6]. In addition, alpine habitats occur at all latitudes allowing for global comparisons [7], which renders them particularly attractive to study evolutionary radiations.

Mountain systems are influenced by several extrinsic factors and processes that have the potential to trigger plant radiations. First, geological processes can cause populations to become geographically isolated, fostering allopatric speciation $[8,9]$. Additionally, orogenic activity creates new environmental space, which can be colonized by pre-adapted local or immigrant lineages, thereby providing key opportunities for diversification [10-12]. Yet, viewing mountain building as sole driver for diversification is likely an oversimplification [13]. Speciation and uplift usually occur on different time scales, and in fact, 
many mountain plant taxa have diversified long after the uplift of their respective mountain range was initiated, as shown for the species-rich areas surrounding the QinghaiTibet Plateau (QTP), [14, 15] and elsewhere [3]. Thus, other mechanisms are likely to have contributed to radiations in mountains. For example, several authors have demonstrated the importance of local or global climate modifications for alpine plant radiations $[16,17]$.

High elevation life zones are characterized by environmental conditions that limit plant growth, such as large diurnal temperature amplitudes or strong seasonality with severe winter frosts, extended snow cover and short growing seasons [18]. Thus, successful colonization, establishment and finally radiation in this life zone might depend on the evolution of traits that allow for adaptation and provide competitive advantages in alpine environments. Novel traits (morphological, physiological, etc.) that allow species to conquer new adaptive zones are referred to as key innovations and they are often regarded as an important first step in adaptive radiations as they allow for ecomorphological divergence and thus speciation $[19,20]$.

Key innovation potential of selected traits can be tested using phylogenetic trees: Positive effects of a particular trait should result in substantially higher diversification rates in groups possessing that trait. Several key innovations have been identified for different montane and alpine plants such as low specific leaf area in Ericaceae Juss. [21], cushion habit in Androsace L. [22], and fruit type, both in Tripterospermum Blume [23] and in Andean bellflowers [24].

The effects of orogeny, climate change, key opportunities and key innovations can interact with each other and may differ between mountain systems, which can result in regionally restricted radiations, so-called geographic radiations [19]. Studying alpine plant groups that occur in several mountain systems may therefore contribute to disentangling the factors triggering alpine radiations. In this study, we will identify rapidly evolving clades and investigate the potential drivers for these radiations in the broadly distributed herbaceous genus Saxifraga.

The large arctic-alpine genus Saxifraga (Saxifragaceae Juss.) comprises up to 500 species [25] and is widely distributed across the Northern Hemisphere. Species diversity is concentrated in the southern European mountain ranges, the Caucasus, the Arctic as well as the QTP region [26]. The Himalayas and the Hengduan Mountains boast particularly high species numbers with up to 75 species in the subnival belt of the Hengduan Mountains alone [27]. Saxifraga was confirmed to be monophyletic, provided the exclusion of Micranthes Haworth [28, 29]. The genus comprises at least 13 sections with species of widely differing morphology and varying levels of species richness, from the monotypic section Saxifragella (Engl.) Gornall \& Zhang to the very large section Ciliatae (175 species) [26]. For example, species of section Porphyrion (90-112 species) are mostly cushion plants not taller than a few centimetres, whereas Irregulares Haworth species (10-20 species) are erect, with large, petiolate basal leaves, and reaching up to $40 \mathrm{~cm}$ in height [26, 30]. Several sections within Saxifraga have radiated within relatively short geological time-frames $[31,32]$, but the underlying factors behind these radiations have not been studied in detail. For these reasons, Saxifraga is an ideally suited study system to investigate patterns and processes connected to alpine radiations. Integrating phylogenetic, biogeographical, and morphological information, we here present a multifaceted approach to studying diversification in Saxifraga. We will focus on the following questions: (1) Do diversification rate shifts explain differences in clade size within Saxifraga? (2) Do diversification rates within Saxifraga vary with geographic distribution? (3) Did the evolution of the cushion life form and limesecreting hydathodes, both of which are potential key innovations in alpine habitats, affect diversification in Saxifraga?

\section{Results \\ Diversification rate patterns in Saxifraga}

Independent of prior choice and assumed total species numbers, BAMM identified two to three rate shifts within Saxifraga (Fig. 1, Additional file 1). Two of these shifts were consistently placed within the same Saxifraga clades across all analyses. The first one (from here on referred to as rate shift 1) was located within sect. Porphyrion subsect. Kabschia sensu Tkach et al. [26], which originated and radiated in Europe (European Alps, Caucasus Mountains) and includes one subgroup that colonized the QTP region and diversified there. The second one (shift 2) was located within a clade that contains members of sect. Ciliatae subsect. Hirculoideae. This clade is the largest subclade of the species-rich section Ciliatae, which originated and radiated in the QTP region [31-33]. A third rate shift (shift 3) was present in some scenarios and placed in varying locations close to the root of the Saxifraga phylogeny, most often on the node separating sections Heterisia (A. M. Johnson) Small, Irregulares and Saxifragella (see Fig. 1) from the rest of the genus.

Analyses with BayesRate confirmed the presence of three diversification rate shifts within Saxifraga (Table 1). Regarding overall rate regimes, the model with three distinct diversification rates had the highest marginal likelihood: one rate shared by both clades affected by rate shifts 1 and 2, one rate shared by sections Heterisia, Irregulares, Saxifragella and Pseudocymbalaria Zhmylev (group $\mathrm{H}+\mathrm{I}+\mathrm{S}+\mathrm{P}$ ), and one rate for the rest of Saxifraga (Bayes factor $(\mathrm{BF})$ min: 11.66, BF max 9.61; Table 1). Additionally, models specifying pure birth processes performed considerably better than those with birth-death processes, with the exception of group $\mathrm{H}+\mathrm{I}+\mathrm{S}+\mathrm{P}$ for which both processes were almost equally likely (Table 1 ). Rate estimates did not differ substantially between BAMM and BayesRate 

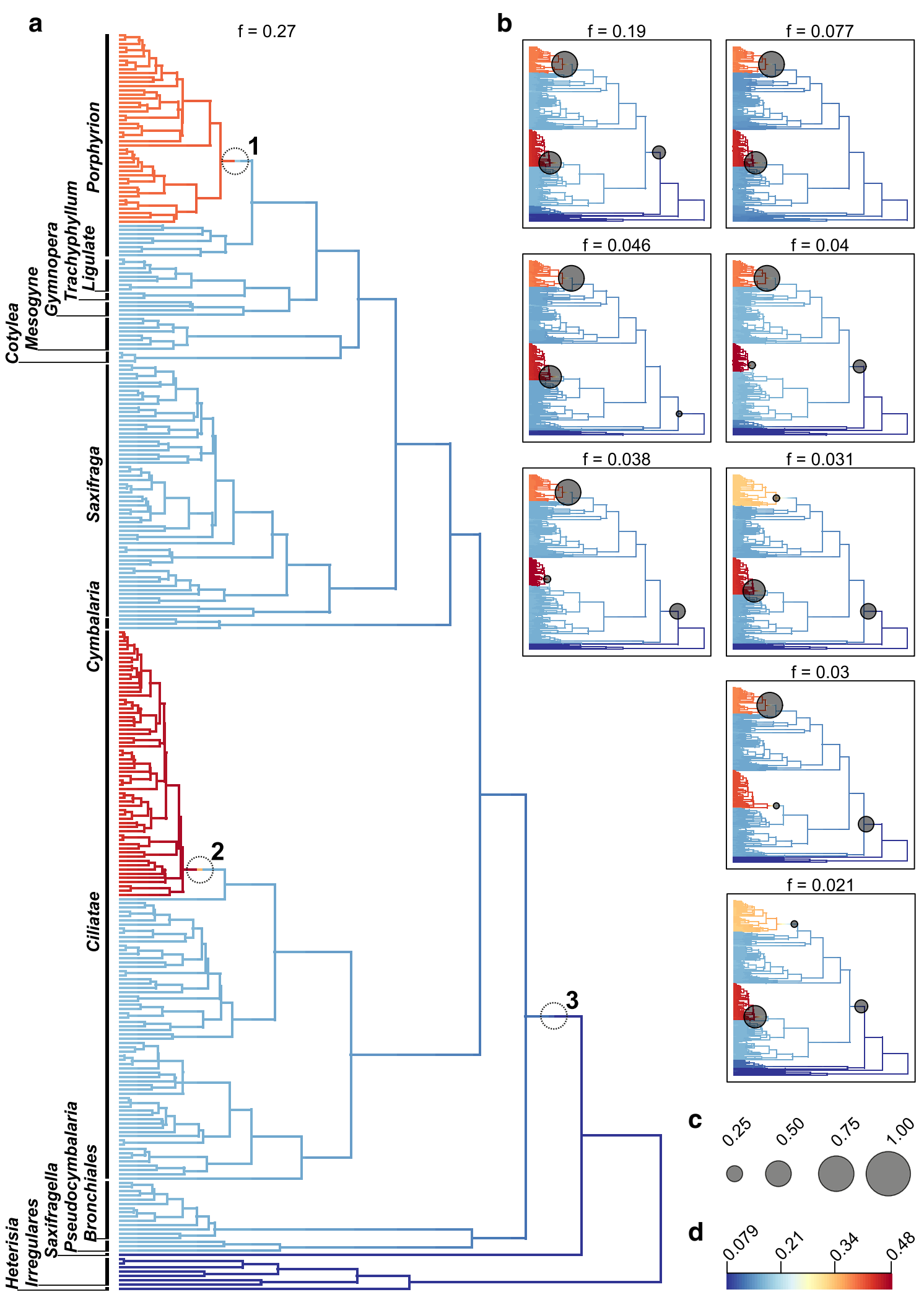

$f=0.021$

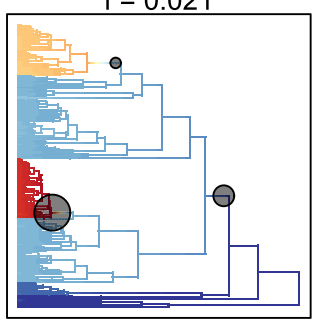

C

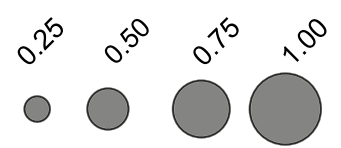

d

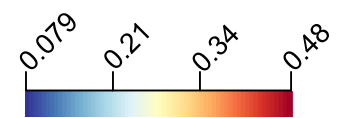

Fig. 1 (See legend on next page.) 
(See figure on previous page.)

Fig. 1 Diversification dynamics in Saxifraga. a Best shift scenario according to BAMM. Dashed circles indicate diversification rate shifts. Saxifraga sections are indicated according to Tkach et al. [26] and Gornall et al. [33]. b The eight next likely shift scenarios. c Size reference for marginal shift probabilities for each shift in B. $\mathbf{d}$ Colour ramp for diversification rates in species per million years. Results presented here are from the analysis with $\gamma=0.5$ and minimum sampling fractions per section. Results from additional BAMM analyses were concordant with those presented here and are summarized in Additional file 1

(Additional file 2). While BayesRate generally produced slightly higher net diversification rate estimates (Additional file 2), the considerable overlap of the $95 \%$ HPD intervals indicates an overall agreement between the two approaches. Importantly, the differences between Ciliatae subsect. Hirculoideae and the other clades were found to be very similar (e.g., an increase over the background rate of 2.6- and 2.4-fold, respectively).

Diversification rate estimates were very similar between minimum and maximum species number analyses (Table 2). Under pure birth processes, net diversification rates in clades Ciliatae subsect. Hirculoideae and Porphyrion subsect. Kabschia were about 2.5 times higher than the background rate (net diversification rates min, max: Hirculoideae and Kabschia clade 0.455, 0.471 species/Myr; background rate $0.171,0.184$ species/Myr; Table 2). Sections Heterisia, Irregulares, Saxifragella and Pseudocymbalaria on the other hand diversified at a rate that was ca. 3 times lower than the Saxifraga background rate (min, max: 0.054, 0.071 species/Myr).

\section{Geography-associated diversification}

The GEOSSE model with the lowest overall AIC value specified a pure birth process in the Hengduan Mountains region (area A) and differential speciation, extinction and transition rates between areas (Additional file 3.1). Two similar models, also with differential speciation and transition rates between areas, also had good model fit $(\triangle \mathrm{AIC}<6$; Additional file 3.1). Initial parameter estimates using maximum likelihood inference of these three best scoring models were highly congruent (Additional file 3.2) and we decided to use the best overall model to run MCMC parameter estimation. Net diversification rates were ca. 3.5 times higher in the Hengduan Mountains region than in the rest of the world (Fig. 2, Table 3). The empirical $\triangle \mathrm{AIC}$ for the Hengduan Mountain dataset was well separated from the distribution of simulated $\triangle \mathrm{AIC}$ values indicating a robust signal in the empirical data for region-dependent diversification (Additional file 4).

Analyses regarding the entire QTP region yielded similar results with respect to the most likely diversification model

Table 1 Comparison of different diversification rate scenarios for Saxifraga using BayesRate

\begin{tabular}{|c|c|c|c|c|c|c|c|c|}
\hline \multirow{2}{*}{$\begin{array}{l}\text { Total } \\
\text { no. } \\
\text { of } \\
\text { shifts }\end{array}$} & \multirow{2}{*}{$\begin{array}{l}\text { Ciliatae } \\
\text { subsect. } \\
\text { Hirculoideae }\end{array}$} & \multirow{2}{*}{$\begin{array}{l}\text { Porphyrion } \\
\text { subsect. } \\
\text { Kabschia }\end{array}$} & \multirow{2}{*}{$\begin{array}{l}\text { Group } \\
\mathrm{H}+\mathrm{I}+\mathrm{S}+\mathrm{P}\end{array}$} & \multirow{2}{*}{$\begin{array}{l}\text { Back- } \\
\text { ground }\end{array}$} & \multicolumn{2}{|l|}{$\min$} & \multicolumn{2}{|l|}{$\max$} \\
\hline & & & & & LogL & BF & $\log L$ & $\mathrm{BF}$ \\
\hline 3 & $\mathrm{~PB}^{*}$ & & $\mathrm{~PB}$ & PB & -665.42 & - & -693.57 & - \\
\hline 3 & $\mathrm{~PB}^{*}$ & & $\mathrm{BD}$ & PB & -666.13 & 1.42 & -694.82 & 2.50 \\
\hline 3 & $P B^{*}$ & & $\mathrm{BD}$ & $\mathrm{BD}$ & -668.67 & 6.50 & -697.40 & 7.66 \\
\hline 3 & $\mathrm{BD}^{*}$ & & $\mathrm{BD}$ & $\mathrm{BD}$ & -670.55 & 10.25 & -698.69 & 10.23 \\
\hline 2 & $P B^{*}$ & & - & PB & -671.25 & 11.66 & -698.38 & 9.61 \\
\hline 2 & $\mathrm{~PB}^{*}$ & & - & $\mathrm{BD}$ & -673.20 & 15.55 & -700.35 & 13.56 \\
\hline 2 & $\mathrm{~PB}$ & $\mathrm{~PB}$ & - & PB & -674.16 & 17.48 & -701.91 & 16.67 \\
\hline 2 & $\mathrm{BD}^{*}$ & & - & $\mathrm{BD}$ & -675.16 & 19.49 & -702.43 & 17.72 \\
\hline 2 & $\mathrm{BD}$ & $\mathrm{BD}$ & - & $\mathrm{BD}$ & -679.17 & 27.50 & -706.92 & 26.70 \\
\hline 1 & PB & - & - & PB & -682.72 & 34.59 & -708.13 & 29.10 \\
\hline 1 & $\mathrm{BD}$ & - & - & $\mathrm{BD}$ & -686.32 & 41.80 & -711.20 & 35.26 \\
\hline 1 & - & PB & - & PB & -700.92 & 71.00 & -725.73 & 64.32 \\
\hline 1 & - & PB & - & PB & -703.61 & 76.37 & -728.10 & 69.05 \\
\hline 0 & - & - & - & PB & -722.36 & 113.88 & -748.80 & 110.46 \\
\hline 0 & - & - & - & $\mathrm{BD}$ & -723.53 & 116.22 & -749.73 & 112.31 \\
\hline
\end{tabular}

Various scenarios for shifts in three Saxifraga clades under pure birth (PB) and birth-death (BD) processes were tested. Asterisks indicate scenarios in which selected clades were constrained to have the same net diversification rates. Log marginal likelihoods (LogL) and results from Bayes factor (BF) tests are given for analyses with minimum and maximum species 
Table 2 Net diversification rate estimates

\begin{tabular}{lll}
\hline & min mean [HPD] & max mean [HPD] \\
\hline Ciliatae subsect. Hirculoideae & $0.455[0.349-0.575]$ & $0.471[0.357-0.593]$ \\
Porphyrion subsect. Kabschia & $0.455[0.349-0.575]$ & $0.471[0.357-0.593]$ \\
Group H + I + S + P & $0.054[0.020-0.090]$ & $0.071[0.032-0.116]$ \\
Background rate & $0.171[0.133-0.211]$ & $0.184[0.144-0.226]$
\end{tabular}

Mean net diversification (speciation - extinction) rates and 95\% highest posterior density (HPD) intervals for the different Saxifraga clades from the BayesRate analysis and parameter estimates (Additional files 5.1 and 2). However, there was no substantial difference in model fit between simulated and empirical data suggesting that asymmetrical transition rates alone, not differential diversification, could have led to the observed distribution pattern (Additional file 4).

\section{Tests for key innovations}

When tested across the entire Saxifraga phylogeny, neither the evolution of lime-secreting hydathodes nor the cushion exhibited significant patterns of differential speciation or extinction rates. However, as pointed out by Beaulieu \& Donoghue [34] and Beaulieu \& O'Meara [35], it can be problematic to use BiSSE to investigate the effects of certain

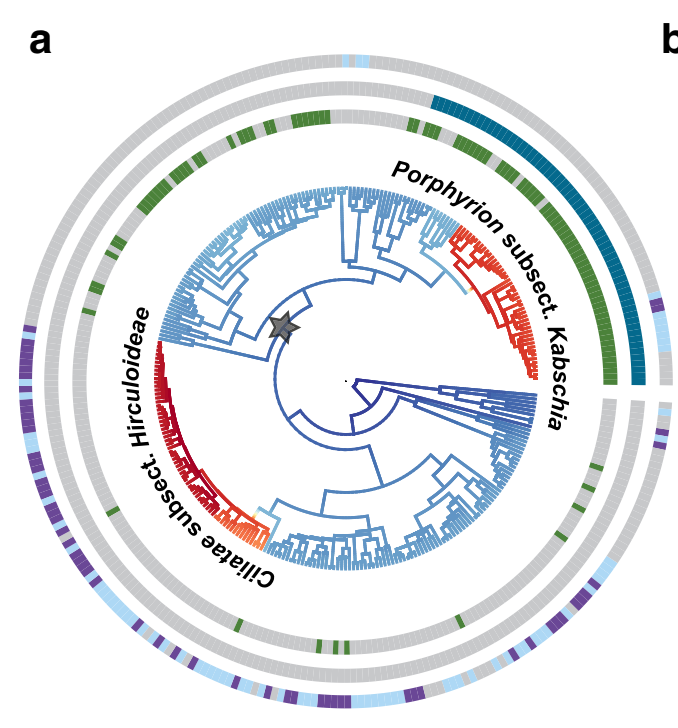

b
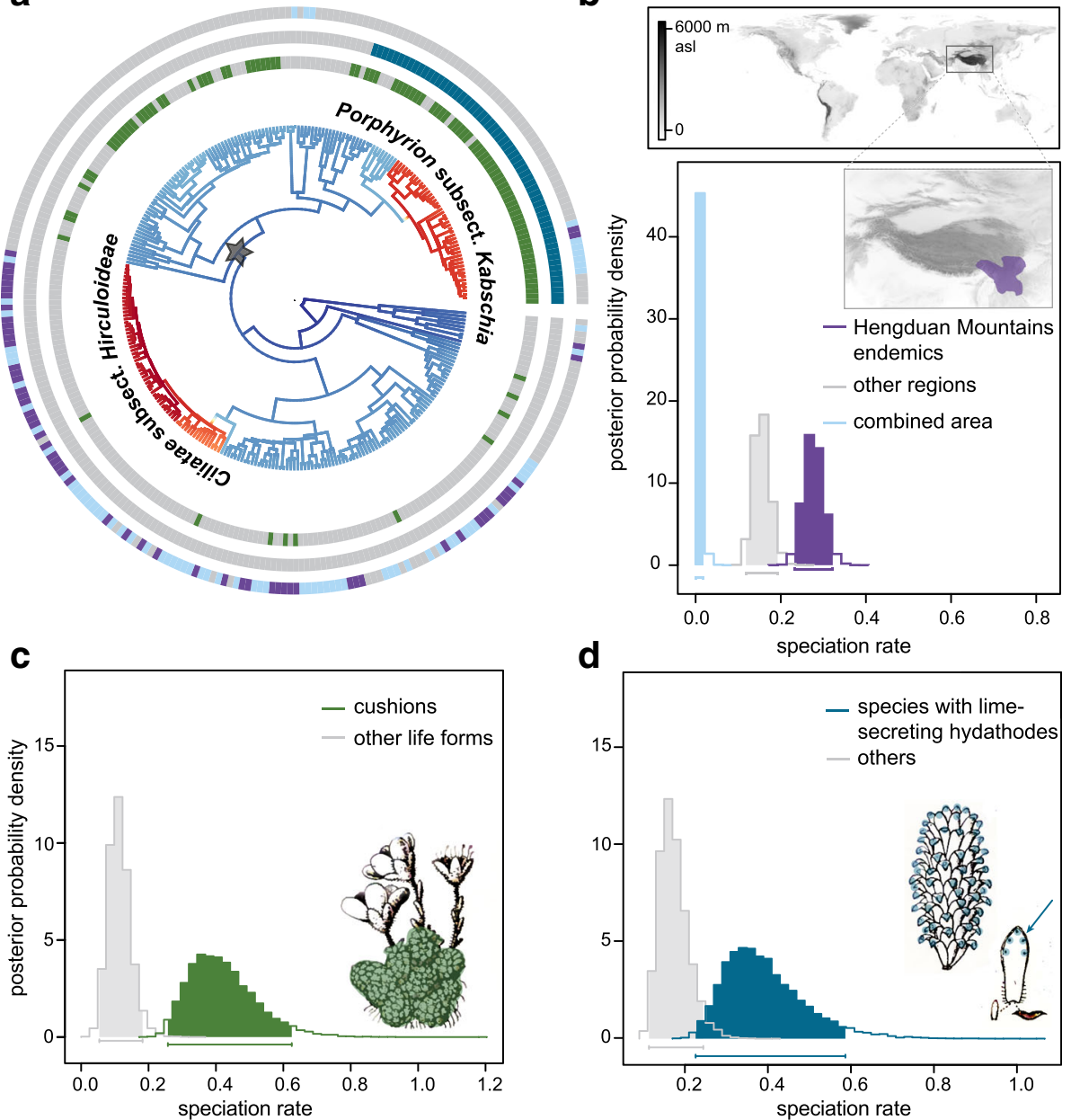

Fig. 2 State-dependent diversification in Saxifraga. a Saxifraga phylogeny with estimated diversification rate regimes according to BAMM (Fig. 1, warmer colours indicate higher rates). Phylogenetic distributions of species' traits are indicated in green (cushion habit) and blue (lime-secreting hydathodes), the geographical distribution (presence in the Hengduan Mountains) is shown in purple. b Speciation rates in the Hengduan Mountain hotspot vs. other regions. c Speciation rates of cushion saxifrages vs. other life forms. Analysis was constrained to parts of the Saxifraga phylogeny indicated by the star in a Drawing depicts habit of S. lilacina [87], cushion indicated by green shading. $\mathbf{d}$ Speciation rates of lineages carrying limesecreting hydathodes vs. others. The analysis was constrained to parts of the Saxifraga phylogeny indicated by the star in a Drawings depict stem of $S$. imbricata, with lime-secreting hydathodes on each leaf tip and a single cauline leaf of S. lilacina bearing five lime-secreting hydathodes [87] 
Table 3 Parameter estimates for best scoring GEOSSE model for state-dependent diversification of Saxifraga in the Hengduan Mountains region

\begin{tabular}{lllll}
\hline & $\lambda$ mean [HPD] & $\mu$ mean [HPD] & $d$ mean [HPD] & $r$ mean [HPD] \\
\hline Hengduan Mountains & 0.277 & - & 0.464 & 0.277 \\
& {$[0.231-0.321]$} & & {$[0.316-0.623]$} & 0.004 \\
Other areas & 0.156 & 0.076 & {$[0.231-0.321]$} & 0.080 \\
& {$[0.118-0.193]$} & {$[0.021-0.133]$} & & {$[0.049-0.11]$} \\
Joined area & 0.006 & & & \\
& {$[0.000-0.018]$} & & & \\
\hline
\end{tabular}

Mean parameter estimates and $95 \%$ highest probability density (HPD) intervals are given for speciation rates $(\lambda)$, extinction rate ( $\mu$ ), transition rates to joined area (d) and net diversification rates $(r ; \lambda-\mu)$ of Saxifraga in the Hengduan Mountains region

traits on phylogenies with multiple rate shifts. Both of the traits that we tested are limited to specific clades of Saxifraga (Fig. 2). Importantly, they are almost entirely absent in Ciliatae and in Ciliatae subsect. Hirculoideae for which rate shift 2 was detected. Restricting the analysis to a smaller part of the tree comprising sections Cymbalaria Griseb., Saxifraga, Cotylea Tausch, Mesogyne Sternb., Gymnopera D. Don, Trachyphyllum (Gaudin) W. D. J. Koch, Ligulatae Haworth and Porphyrion yielded a different result: Plants with lime-secreting hydathodes and cushion saxifrages had substantially higher diversification rates (Fig. 2, Table 4). In addition, trait simulations showed that the empirical $\triangle$ AIC were substantially different from simulated $\triangle \mathrm{AIC}$ values revealing a strong signal for differential diversification rates under these two traits for this part of the Saxifraga phylogeny (Additional file 4).

\section{Discussion}

As a species-rich group with an affinity to high altitude habitats, Saxifraga is well suited to study underlying patterns and factors related to alpine radiations and the diversification process in general. Our study shows that multiple rate shifts led to radiations within Saxifraga and that specific combinations of extrinsic and intrinsic factors drove these radiations. To our knowledge, this is the most extensive study on diversification rates with regard to the species-rich, yet still poorly understood, alpine areas surrounding the QTP to date.

\section{Diversification rate patterns in Saxifraga}

We found a slight increase in the inferred number of rate shifts when increasing the hyperprior on the expected number of rate shifts (Additional file 1A), but prior choice did not affect model selection (scenario with maximum posterior probability; Additional file $1 \mathrm{~B} \& \mathrm{C}$ ). This was further corroborated in a recent study by Mitchell \& Rabosky [36]. While both model selection via Bayes factors, as well as pure-birth models of diversification would also be available in BAMM, BayesRate additionally allows for speciation and extinction rates to be linked between clades. In our case, this revealed that speciation and extinction rates of clades Ciliatae subsect. Hirculoideae and Porphyrion subsect. Kabschia were not significantly different (i.e., a model with same rates was preferred over one with independent rates for both clades).

We found evidence for three distinct diversification rate shifts within Saxifraga. Two of these rate shifts led to substantially increased diversification rates within Saxifraga sections Ciliatae and Porphyrion which had previously been suggested as having experienced rapid radiations [31, 32].

Table 4 Parameter estimates for best scoring models for state-dependent diversification for cushion life form and lime-secreting hydathodes in Saxifraga

\begin{tabular}{lllll}
\hline & $\lambda$ mean [HPD] & $\mu$ mean [HPD] & $q$ mean [HPD] & $r$ mean [HPD] \\
\hline Cushions & 0.420 & 0.219 & 0.056 & 0.201 \\
& {$[0.247-0.614]$} & {$[0-0.452]$} & {$[0.024-0.096]$} & {$[0.094-0.312]$} \\
Other life forms & 0.114 & 0.065 & 0.055 & 0.048 \\
& {$[0.051-0.179]$} & {$[0-0.188]$} & {$[0.002-0.119]$} & {$[-0.074-0.143]$} \\
Hydathodes & 0.393 & 0.159 & 0.003 & 0.234 \\
Non-hydathodes & {$[0.226-0.587]$} & {$[0-0.395]$} & {$[0-0.009]$} & {$[0.118-0.356]$} \\
& 0.173 & 0.063 & 0.006 & 0.110 \\
& {$[0.113-0.244]$} & {$[0-0.150]$} & {$[0-0.015]$} & {$[0.057-0.163]$} \\
\hline
\end{tabular}

Mean parameter estimates and $95 \%$ highest probability density (HPD) intervals are given for speciation rates $(\lambda)$, extinction rates ( $\mu$ ); transition rates (q) and net diversification rates $(r ; \lambda-\mu)$ 
Therefore, diversification rate shifts at least partially explain clade size differences in Saxifraga.

Only a few diversification rate estimates have been published for other taxa with pronounced radiations in the QTP region. The rate estimates reported here (mean estimates min, max: $0.455,0.486$ species/Myr) were similar to those found in other alpine radiations from the QTP region such as in Gentiana L. (0.37 species/Myr) [37] and in several subgenera of Delphinium L. (subg. Delphinastrum (DC.) Peterm. and Oligophyllon Dimitrova 0.37-0.81 species/Myr, subg. Aconitum 0.42-1.11 species/Myr, all assuming low extinction) [38]. In contrast, diversification rates were very low (0.066 species/Myr) in Rhododendron L. despite the taxon being famously species-rich in the QTP region [21]. In addition, the rate estimates reported here do not match the exceptionally high rates that have been reported for several Andean plant groups (e.g., Lupinus L.: 1.56-5.21 species/Myr [39]; Gentianella Moench 1.48-3.21 species/Myr [40]) despite the fact that the Andes and the Hengduan Mountains share several environmental features (e.g., young age, high physiographic heterogeneity). This suggests that comparisons of alpine radiations across the globe might also need to incorporate regional dynamics (e.g., geologic and glaciation history, biogeographic connectivity).

An additional rate shift was present towards the root of the phylogeny, separating sections Heterisia, Irregulares, Saxifragella and Pseudocymbalaria (group $\mathrm{H}+\mathrm{I}+\mathrm{S}+\mathrm{P}$ ) with very low net diversification rates from the rest of Saxifraga. Pure birth and birth-death processes were almost equally likely in this clade, so this depauperate clade may result from very low speciation, relatively high extinction or a combination thereof. In general, pure birth processes had superior model fit in Saxifraga and this matches very low extinction rate estimates that have been found for several other alpine plant groups [21, 37]. However, extinction rates are difficult to estimate from molecular phylogenies and rate estimates are often low with large confidence intervals $[35,41,42]$ but see [43].

\section{Drivers of diversification within Saxifraga}

Similar to Saxifraga, multiple infrageneric rate shifts yielding substantial increases in diversification rates were shown in other species-rich alpine or subalpine genera such as Rhododendron L. [21], Lupinus L. [39] and Hypericum L. [16], suggesting that some plant groups might be particularly prone to radiate. This could be due to intrinsic or extrinsic factors or factor combinations that are shared by all infrageneric clades involved in these radiations. In Saxifraga, this seems unlikely as clades affected by rate shifts are morphologically and phylogenetically distinct with contrasting distribution patterns and biogeographic histories [26, 31]. Rather, it appears plausible that each rate shift was triggered by a specific combination of intrinsic and extrinsic factors including geographical distribution and key innovations as will be discussed in the next section.

\section{Influence of the Hengduan Mountains region on diversification}

Occurrence in the Hengduan Mountains region had a positive effect on Saxifraga diversification. Section Ciliatae subsect. Hirculoideae affected by rate shift 2 is distributed almost entirely in the QTP region with a large proportion of species occurring in the Hengduan Mountains [30, 44]. While some Ciliatae taxa recently colonized other areas including East Asia, Northern Asia and even North America, they did not diversify in those areas [31]. Thus, local key opportunities in the Hengduan Mountains region at the time of diversification may have triggered the diversification rate increase in this group. While rapid radiations have been documented for several plant groups distributed in these mountains [3], ours is the first study to formally compare diversification rates of taxa distributed in the Hengduan Mountains region with those of close relatives of other areas.

The Hengduan Mountains stand out from other mountain ranges in the QTP region due to several characteristics. In contrast to the plateau, parts of which had reached $4000 \mathrm{~m}$ altitude as early as $40 \mathrm{MY}$ ago $[14,45]$ and the Himalayas, which were uplifted to significant altitudes during the Miocene [15], the Hengduan Mountains are considered to be relatively young (Miocene, late Pliocene) $[46,47]$. These different geological histories have led to strongly contrasting biogeographic patterns throughout the region. While recent in situ diversification was disproportionally more important for the species assembly in the Hengduan Mountains, Himalayan biodiversity was largely influenced by immigration [48]. The Hengduan Mountains and the eastern Himalayas have been under the influence of the monsoon system (i.e., greater summer rainfall) since their orogeny, whereas the QTP proper and the western Himalayas are almost entirely beyond the reach of the summer monsoon. In addition, extinctions during Pleistocene glaciations were likely low due to north-south orientation of the valleys of the Hengduan Mountains region [48]. Finally, the Hengduan Mountains have been described as highly heterogeneous in terms of topography, featuring deeply dissected landscapes with steep elevational gradients [3].

Recently, the interplay of high physiographic heterogeneity and episodes of rapid climate oscillations (promoting the "species pump" effect) has been highlighted as a potential driver of alpine diversification [19, 49]. Acting together, these two factors may enhance diversification in mountains by repeatedly modifying dispersal barriers, thus promoting allopatric speciation while buffering extinction through the availability of nearby refugia resulting in a large number of 
species with an island-like distribution and a high chance of survival. Among others, global climate oscillations have been reconstructed for the Early Pliocene as well as for the Pleistocene [50, 51]. This time corresponds roughly to the period that was suggested as origin of the majority of species within subsect. Hirculoideae ( $<5$ Myr ago) [31]. Therefore, both high habitat heterogeneity and climate oscillations were present during the early stages of the radiation of Saxifraga in the Hengduan Mountains. Extant Saxifraga distribution patterns fit the expected results of the "species pump" effect and long-term survival: There are at least 35 Saxifraga species endemic to the subnival belt of the Hengduan Mountains, many of them with highly restricted distribution areas [30, 44].

However, while subsect. Hirculoideae showed a substantial shift in its diversification rate, the remaining subgroups of sect. Ciliatae that also predominantly occur in the QTP region (and particularly in the Hengduan Mountains) did not. This strongly suggests that the presence in these mountains is not sufficient to explain the diversification rate pattern in this section and that geographic radiations might require additional factors other than extrinsic key opportunities. Subsection Hirculoideae is not characterized by any obvious morphological or physiological traits that could serve as clade-specific key innovations. Another driver that has been found to be associated to plant radiations and shifts in diversification rates are whole genome duplications [52]. A survey of polyploidy in the flora of the Hengduan Mountains showed that, contrary to expectations, the frequency of polyploidy in the flora was low (22\%) [53]. For Saxifraga, the authors found that the proportion of polyploid species was higher than average (44\%) but still lower that what would have been expected judging from other high mountain floras (45-85\%) [53]. However, chromosome numbers were only available for nine Saxifraga species distributed in the Hengduan Mountains, so further work will be required to examine this pattern in more detail. Regarding hybridization, another mechanism often connected to rapid speciation in plants, we were only able to find one report of a potential trace of such an event in S. egregia of sect. Ciliatae [54], however more data is needed to clarify this. Finally, niche shifts or changes in niche width could also be an important factor involved in diversification rate shifts, as demonstrated, for instance, by Matuszak et al. [23] and Favre et al. [37] who found that increased diversification rates corresponded to niche shifts in two species-rich genera of Gentianinae G. Don (i.e., Gentiana and Tripterospermum). For Saxifraga, Rubio de Casas et al. [55] showed that the cliff and rock face habitat was most common but that a switch to tundra habitats (which exhibited high within-habitat diversification) occurred within a large unresolved clade containing species of sections Ciliatae, Saxifraga and Porphyrion. Since the exact location of this shift within the phylogeny remained unclear, ecological niches will have to be studied in more detail for these sections to investigate this pattern more closely.

\section{Key Innovations in alpine environments}

Saxifraga rate shift 1 was observed in Porphyrion subsect. Kabschia, which is largely distributed in European and Asian mountain systems, with only one subclade occurring in the QTP region, where the subsection is more diverse in the Himalayas than in the Hengduan Mountains [56]. Due to this wide and uneven distribution pattern, it is unlikely that key opportunities connected to geographic distribution have triggered the rate shift in this group. Rather, morphological traits likely acted as key innovations causing the observed rate shift in Porphyrion subsect. Kabschia. First, the cushion life form, which is widespread throughout the genus, was associated with differential rates of diversification in certain clades of Saxifraga. Cushion plants are widespread in arctic and alpine habitats and this life form has been shown to be an adaptation to cold climates through reduction in water loss and desiccation [57]. Similar to Saxifraga, the cushion life form was found to foster lineage diversification in the species-rich alpine genus Androsace $[22,58]$. The results derived from both genera corroborate the findings of Boucher et al. [57] who showed that the cushion life form arose more than 100 times independently across Angiosperms and concluded that it is likely to be a convergent key innovation for occupancy of extremely cold environments.

Rather than a single key innovation driving radiations, it has been suggested that several sequentially acquired traits may act together as drivers of lineage diversification [59]. Beside the cushion habit, lime-secreting hydathodes, which are restricted to sections Ligulatae and Porphyrion, were also associated with higher diversification rates in some clades of Saxifraga. Hydathodes, in general, are associated with guttation, or water discharge from the leaf interior, and occur widely in Saxifraga [60]. Lime-secreting hydathodes which are morphologically distinct from simple hydathodes serve as a means for excreting excess calcium salts leaving characteristic white encrustations on the leaves [61]. This mechanism is particularly interesting considering that many Saxifraga species, in particular those of sections Porphyrion, Ligulatae, Trachyphyllum and Gymnopera, occur in habitats with little soil, including cliff ledges and rock crevices, and display strong substrate specificity with regards to calcareous or siliceous substrates. Conti et al. [61] suggested that lime-secreting hydathodes represent the derived state of hydathodes in Saxifraga and current phylogenetic placement of the aforementioned sections suggests that they evolved either once in the ancestor of these four sections and were subsequently lost twice (in sections 
Mesogyne and Trachyphyllum), or less likely, that limesecretion evolved twice independently in Porphyrion and in Ligulatae. Following the first scenario, it would be likely that the ancestor of these four sections was calcicole. However, at this point substrate preference data are not complete for species of sect. Porphyrion. While there is a general trend that species possessing lime-secreting hydathodes occur on base-rich, calcareous soils or rock, there are several exceptions to this pattern: Several species with lime-secreting pores are not bound to base-rich substrates (e.g., S. juniperifolia, S. cotyledon, S. florulenta) and species that do not possess lime-secreting hydathodes can occur alongside others that do on calcareous soils (e.g., $S$. exarata subsp. moschata) [60]. Thus, this mechanism and its implications clearly deserve closer attention, in particular considering its positive correlation with diversification in Saxifraga as shown in this study.

In general, it is important to point out that while we have achieved substantial taxon coverage of Saxifraga, there are some species missing from our dataset, in particular from sections for which rate shifts were inferred (e.g., section Irregulares: sampling proportion: 0.350.7\%, section Porphyrion: 0.47-0.58\%, Additional file 6). Sampling bias can affect the detection of rate shifts as well as the location of identified shifts $[62,63]$ and caution when interpreting the results is therefore advised. However, we took this into account as thoroughly as possible by supplying section-specific sampling proportions during all analyses and running minimum and maximum species number analyses. Furthermore, most sections of Saxifraga are morphologically distinct and molecular work so far confirmed the current taxonomic delineation [26]. Thus, it is unlikely that these missing taxa would affect our results.

\section{Conclusion}

Our study highlights the complexity of plant radiations. Even in closely related lineages occupying the same life zone, shifts in diversification rates are not necessarily governed by the same factors. In particular, radiation within one subgroup of Saxifraga (section Ciliatae subsect. Hirculoideae) was driven by extrinsic opportunities associated with the Hengduan Mountains region as well as additional factors, possibly niche shifts. A second infrageneric radiation (in sect. Porphyrion subsect. Kabschia) was likely independent of these processes. Instead, the cushion habit and the acquisition of lime-secreting hydathodes emerged as likely key innovations indicating that the radiation in this clade might have been adaptive (sensu Simões et al. [19]). The case of Saxifraga thus shows that alpine plant radiations have complex underlying causes, which are to be viewed in both, geographical and biotic contexts. Future studies of (alpine) plant radiations should therefore attempt to identify combinations of intrinsic and extrinsic factors relevant to the diversification process.

\section{Methods \\ Dataset}

For this study, we used the same Saxifragaceae data set as in Ebersbach et al. [31], consisting of 420 taxa and an aligned length of 4225 bp of markers ITS, trnL-trnF, and matK. Prior to analyses, we modified the posterior distribution of post-burnin BEAST trees from Ebersbach et al. [31] by removing all taxa not belonging to Saxifraga as well as several duplicate taxa. In addition, three taxa (S. haplophylloides, S. diffusicallosa and S. maxionggouensis) from the dataset of Gao et al. [32] were added to all trees using the bind.tip function of the phytools package [64] in $R$ [65]. This function allows to add tips to a phylogeny while rescaling the tree to conserve its ultrametric properties. According to Gao et al. [32] these three taxa are all part of subsect. Hirculoideae which form a well-defined subclade of Saxifraga section Ciliatae, but their exact position is unclear due to low resolution. We therefore placed these taxa randomly within that subclade (also using randomly generated node heights) to mirror the existing uncertainty. The final dataset consisted of 297 Saxifraga taxa. Analyses were run on the maximum clade credibility (MCC) tree generated by TreeAnnotator v1.8.2 [66] as well as on a set of 100 trees randomly sampled from all trees in the posterior distribution.

\section{Diversification rates}

We used BAMM (v.2.5.0) [67] and the R package BAMMtools [68] as well as the programme BayesRate (v.1.6.3, [43]) to assess diversification rate heterogeneity across the Saxifraga phylogeny. BAMM identifies distinct configurations of rate shifts without the need for an a priori specification of their number and location. Any sampling bias is likely to affect the accuracy of rate estimates [69], so we specified section-specific sampling fractions to account for incomplete taxon sampling. However, given that published species numbers for some sections differ widely (Additional file 6, e.g., [26, 30, 70, 71]), we calculated sampling fractions for minimum and maximum published species numbers per section and ran all analyses with both values.

We ran four MCMC chains with 20 million generations each, saving the output every 1000th generation. The first $10 \%$ of samples were discarded as burn-in and the effective sample sizes for the number of shifts and the log likelihood were calculated to assess convergence. It has been suggested that the likelihood function of BAMM might be incorrect and that the programme suffers from strong prior sensitivity and unreliable rate estimates [72]. However, Rabosky et al. (in press) [73] recently reported that they were unable to reproduce the prior sensitivity and that the 
shortcomings indicated by Moore et al. [72] were likely due to a misapplication of the programme and poorly designed test data. We performed two additional analyses to address these issues: First, we ran the analyses under a range of settings for the prior distribution on the number of rate shifts $(\gamma=10,2,1,0.5,0.1)$ to assess the potential prior sensitivity. Second, we used the programme BayesRate to further evaluate the various rate shift scenarios. BayesRate was specifically designed for hypothesis-based testing of diversification regimes (i.e., rate shifts through time, rate differences between particular clades, etc.) across a given phylogeny or set of phylogenies. Importantly, BayesRate employs a different likelihood function [42] than BAMM, and thus provides an independent test of the diversification model (number of rate shifts) and the associated rates. Finally, BayesRate allows for a straightforward incorporation of phylogenetic (topological and temporal) uncertainty, while there is currently no direct way of accounting for phylogenetic uncertainty in BAMM. We used BayesRate to test the most likely number of rate regimes and to compare the likelihood of pure birth (yule) and birth-death via thermodynamic integration. After identifying the best-fit model via a Bayes factor test [74], we estimated the model parameters across all 100 randomly sampled phylogenetic trees to account for phylogenetic uncertainty.

\section{Key innovations}

We tested the effect of two potential key innovations (cushion habit and the presence of lime-secreting hydathodes) on Saxifraga diversification. Trait information was assembled from several floras as well as specific Saxifraga literature [30, 60, 75-77]. We supplied state-specific sampling proportions to account for missing species and sampling bias (sampling proportions: cushion plants: 0.8, non-cushions 0.5 ; plants with lime-secreting hydathodes: 0.85; plants without lime-secreting hydathodes: 0.55 ). To asses trait-associated diversification, we fitted the Multiple State Speciation and Extinction (MuSSE) model [78] on 100 phylogenetic trees in a Bayesian framework (as outlined in [79], script available at https://github.com/dsilvestro/ mcmc-diversitree). MuSSE is a multistate extension of the BiSSE (Binary State Speciation and Extinction) model [80], which simultaneously estimates the rates of speciation $(\lambda)$ and extinction $(\mu)$ under two character states $(0$ and 1$)$ as well as transition rates between these states $\left(\mathrm{q}_{01}\right.$ and $\left.\mathrm{q}_{10}\right)$.

Recently, serious concerns about the statistical power and interpretations of state-dependent speciation and extinction (SSE) models have been raised [81-83]. The statistical power of BISSE and other SSE models is relatively low when using small phylogenies with less than 300 tips and/ or trait states that are unevenly represented in the phylogeny (high tip ratio). Furthermore, SSE models have been shown to be affected by high Type 1 error rates that stem from not accounting for independent shifts in character states that are not associated to diversification per se [83]. In order to account for this, we employed a simulation scheme suggested by Rabosky \& Goldberg [83] exploiting the Maximum Likelihood framework of BiSSE in the $\mathrm{R}$ package diversitree [78]. The empirically estimated mean transition rates $\mathrm{q}_{10}$ and $\mathrm{q}_{01}$ were used to simulate 100 sets of traits across the Saxifraga phylogeny using the R package phytools [64]. The simulated traits were then used to fit two models each, the unconstrained diversification model $\left(\lambda_{0} \neq \lambda_{1}, \mu_{0} \neq \mu_{1}, q_{0} \neq q_{1}\right)$ and the best scoring model for each trait. We used the distribution of $\triangle$ AIC values (difference in AIC between both models) to investigate the discriminative power of these models and compared this with the results from our empirical analysis.

\section{Geographical distribution}

GeoSSE, another member of the SSE model class, is specifically designed to investigate the association of geographical distribution patterns with lineage diversification [84]. It estimates rates of speciation in the target area (area A) and the remaining distribution (area $\mathrm{B}$ ) as well as in the joint range (area $\mathrm{AB}$ ). Range contraction is modelled as local extinction $(\mathrm{AB} \rightarrow \mathrm{B}, \mathrm{AB} \rightarrow \mathrm{A})$ while transition rates between each area and the joint area $(\mathrm{A} \rightarrow \mathrm{AB}, \mathrm{B} \rightarrow \mathrm{AB})$ correspond to range expansion. We used GeoSSE as implemented in the $\mathrm{R}$ package diversitree [78] to test for an association between diversification in Saxifraga and occurrence in the Hengduan Mountains region. Distribution data were retrieved from various floras $(30,60,75,76$; sampling proportion of Saxifraga from Hengduan Mountains region: 0.5, in other areas: 0.7 , widespread species in combined area: 0.7). In order to test the robustness of our results we performed an additional analysis testing for an effect of occurrence in the QTP region in general, here broadly defined as the QTP itself, the Hengduan Mountains, the Himalayas, the Karakorum Range, Pamir, the Tianshan, and the Altai Mountains (sampling proportion of Saxifraga from QTP region: 0.65 , in other areas: 0.8 , widespread species in combined area: 0.9). Area delineation of the Hengduan Mountains region was done in accordance with Boufford [85]. In total, we compared 36 constrained GeoSSE models (e.g., equal speciation, extinction, and/or transition rates) to a fully unconstrained model (differential speciation, extinction and transition rates) using the AIC and Akaike weights [86]. Consecutively, parameter estimation was performed via an MCMC analysis of 50,000 generations for the model with the lowest AIC. The first 500 steps were discarded as burn-in and trait simulations were run as described above.

\section{Additional files}

Additional file 1: Results of prior sensitivity tests and species number comparisons in BAMM (PDF 1143 kb) 
Additional file 2: Diversification rate estimates for Saxifraga from BayesRate and BAMM (DOCX $32 \mathrm{~kb})$

Additional file 3: 1. Best scoring GEOSSE models for state-dependent diversification of Saxifraga in Hengduan Mountains. 2. Initial parameter estimates of GEOSSE models for state-dependent diversification of Saxifraga in Hengduan Mountains (DOCX 39 kb)

Additional file 4: Results for model fitting of simulated traits in Saxifraga (PDF $416 \mathrm{~kb}$ )

Additional file 5: 1. Best scoring GEOSSE models for state-dependent diversification of Saxifraga in QTP region. 2. Parameter estimates for best scoring GEOSSE model for state-dependent diversification of Saxifraga in QTP region (DOCX $35 \mathrm{~kb}$ )

Additional file 6: Minimum and maximum species numbers for all Saxifraga sections (DOCX 29 kb)

\section{Abbreviations}

QTP: Qinghai-Tibet Plateau; H + I + S + P: Clade consisting of sections Heterisia, Irregulares, Saxifragella, Pseudocymbalaria; BF: Bayes factor; PB: Pure birth (or Yule) diversification process; BD: Birth-death diversification process; HPD: Highest posterior density; SSE model: State-dependent speciation and extinction model

\section{Acknowledgements}

We would like to thank Ingo Michalak (formerly Leipzig University) for methodological assistance during early stages of this study as well as Natalia Tkach (Martin Luther University Halle) for continued advice and constructive discussions. Furthermore, we would like to thank Hang Sun and Ende Liu (both Kunming Institute of Botany) for their assistance with Chinese samples and data retrieval from foreign language sources.

\section{Funding}

Financial support for this study was provided by the German Science Foundation (project no. MU 2934/3-1) and by the research funding programme 'LOEWE Landes-Offensive zur Entwicklung Wissenschaftlich-oekonomischer Exzellenz' of Hesse's Ministry of Higher Education, Research, and the Arts to Alexandra N. Muellner-Riehl.

\section{Availability of data and materials}

The dataset analysed during the current study is available from A.N Muellner-Riehl upon reasonable request.

\section{Authors' contributions}

AF, ANM-R and JE designed the study. JE and JS analysed the data and JE, JS and $A F$ interpreted the results. JE wrote the first draft of the manuscript and all authors contributed to writing the final version.

\section{Authors' information}

Jana Ebersbach is a PhD candidate at Leipzig University. She is mainly studying the taxonomy, biogeography and diversification history of Saxifraga with a particular focus on the influence of past climatic and geological changes in the region of the Qinghai-Tibet Plateau.

\section{Competing interests}

The authors declare that they have no competing interests.

\section{Publisher's Note}

Springer Nature remains neutral with regard to jurisdictional claims in published maps and institutional affiliations.

\section{Author details}

${ }^{1}$ Department of Molecular Evolution and Plant Systematics \& Herbarium (LZ), Institute of Biology, Leipzig University, Johannisallee 21-23, D-04103 Leipzig, Germany. ${ }^{2}$ German Centre for Integrative Biodiversity Research (iDiv) Halle-Jena-Leipzig, Deutscher Platz 5e, D-04103 Leipzig, Germany.
Received: 18 November 2016 Accepted: 12 May 2017

Published online: 25 May 2017

\section{References}

1. Linder HP. Plant species radiations: where, when, why? Philos Trans R Soc Lond Ser B Biol Sci. 2008;363:3097-105.

2. Zanne AE, Tank DC, Cornwell WK, Eastman JM, Smith SA, FitzJohn RG, et al. Three keys to the radiation of angiosperms into freezing environments. Nature. 2014:506:89-92. doi:10.1038/nature12872.

3. Hughes $C E$, Atchison GW. The ubiquity of alpine plant radiations: from the Andes to the Hengduan Mountains. New Phytol. 2015;207:275-82.

4. Kohler T, Maselli D, editors. Mountains and climate change: From understanding to action. Bern: CDE; 2009.

5. Barthlott W, Mutke J, Rafiqpoor D, Kier G, Kreft H. Global centers of vascular plant diversity. Nova Acta Leopold. 2005;92:61-83.

6. Spehn EM, Rudmann-Maurer K, Körner C. Mountain biodiversity. Plant Ecol Divers. 2011:4:301-2. doi:10.1080/17550874.2012.698660.

7. Körner C. Mountain Biodiversity, its causes and function. Ambio Spec Rep. 2004:11-7.

8. Luebert F, Muller LAH. Effects of mountain formation and uplift on biological diversity. Front Genet. 2015;6:54. doi:10.3389/fgene.2015.00054.

9. Wen J, Zhang J, Nie Z, Zhong Y, Sun H. Evolutionary diversifications of plants on the Qinghai-Tibetan Plateau. Front Genet. 2014; doi:10.3389/fgene. 2014.00004.

10. Hughes C, Eastwood R. Island radiation on a continental scale: exceptional rates of plant diversification after uplift of the Andes. Proc Natl Acad Sci U S A. 2006;103:10334-9.

11. Winkworth R. Evolution of the New Zealand mountain flora: Origins, diversification and dispersal. Org Divers Evol. 2005;5:237-47. doi:10.1016/j. ode.2004.12.001

12. Uribe-Convers S, Tank DC. Shifts in diversification rates linked to biogeographic movement into new areas: An example of a recent radiation in the Andes. Am J Bot. 2015;102:1854-69. doi:10.3732/ajb.1500229.

13. Hoorn C, Mosbrugger V, Mulch A, Antonelli A. Biodiversity from mountain building. Nat Geosci. 2013;6:154. doi:10.1038/ngeo1742.

14. Renner SS. Available data point to a 4-km-high Tibetan Plateau by $40 \mathrm{Ma}$, but 100 molecular-clock papers have linked supposed recent uplift to young node ages. J Biogeogr. 2016;

15. Favre A, Päckert M, Pauls SU, Jähnig SC, Uhl D, Michalak I, et al. The role of the uplift of the Qinghai-Tibetan Plateau for the evolution of Tibetan biotas. Biol Rev Camb Philos Soc. 2015;90:236-53. doi:10.1111/brv.12107.

16. Nürk NM, Uribe-Convers S, Gehrke B, Tank DC, Blattner FR. Oligocene niche shift, Miocene diversification - cold tolerance and accelerated speciation rates in the St. John's Worts (Hypericum, Hypericaceae). BMC Evol Biol. 2015; 15:190. doi:10.1186/s12862-015-0359-4.

17. Wang $L$, Schneider $H$, Zhang $X$, Xiang $Q$. The rise of the Himalaya enforced the diversification of SE Asian ferns by altering the monsoon regimes. BMC Plant Biol. 2012:12:210. doi:10.1186/1471-2229-12-210.

18. Nagy L, Grabherr G. The biology of alpine habitats. Oxford: Oxford University Press; 2009.

19. Simões $M$, Breitkreuz $L$, Alvarado M, Baca S, Cooper JC, Heins L, et al. The evolving theory of evolutionary radiations. Trends Ecol Evol. 2016;31:27-34. doi:10.1016/j.tree.2015.10.007

20. Hodges SA, Arnold ML. Spurring plant diversification: Are floral nectar spurs a key innovation? Proc R Soc B. 1995:262:343-8.

21. Schwery O, Onstein RE, Bouchenak-Khelladi Y, Xing Y, Carter RJ, Linder HP. As old as the mountains: the radiations of the Ericaceae. New Phytol. 2015; 207:355-67. doi:10.1111/nph.13234

22. Boucher FC, Thuiller W, Roquet C, Douzet R, Aubert S, Alvarez N, et al. Reconstructing the origins of high-alpine niches and cushion life form in the genus Androsace s.l. (Primulaceae). Evolution. 2012;66:1255-68. doi:10. 1111/j.1558-5646.2011.01483.x.

23. Matuszak S, Favre A, Schnitzler J, Muellner-Riehl AN. Key innovations and climatic niche divergence as drivers of diversification in subtropical Gentianinae in southeastern and eastern Asia. Am J Bot. 2016;103:899-911. doi:10.3732/ajb.1500352

24. Lagomarsino LP, Condamine FL, Antonelli A, Mulch A, Davis CC. The abiotic and biotic drivers of rapid diversification in Andean bellflowers (Campanulaceae). New Phytol. 2016;210:1430-42. doi:10.1111/nph.13920.

25. Vargas P. A phylogenetic study of Saxifraga sect.Saxifraga (Saxifragaceae) based on nrDNA ITS sequences. Plant Syst Evol. 2000;223:59-70. 
26. Tkach N, Röser M, Miehe G, Muellner-Riehl AN, Ebersbach J, Favre A, Hoffmann MH. Molecular phylogenetics, morphology and a revised classification of the complex genus Saxifraga (Saxifragaceae). Taxon. 2015: 1159-87. doi: 10.12705/646.4.

27. $\mathrm{Xu} \mathrm{B}, \mathrm{Li}$ Z, Sun H. Plant diversity and floristic characters of the alpine subnival belt flora in the Hengduan Mountains, SW China. J Syst Evol. 2014; 52:271-9. doi:10.1111/jse.12037.

28. Soltis DE, Kuzoff RK, Conti E, Gornall RJ, Ferguson IK. matK and rbcL gene sequence data indicate that Saxifraga (Saxifragaceae) is polyphyletic. Am J Bot. 1996;83:371-82.

29. Prieto JAF, Arjona JM, Sanna M, Perez R, Cires E. Phylogeny and systematics of Micranthes (Saxifragaceae): an appraisal in European territories. J Plant Res. 2013;126:605-11. doi:10.1007/s10265-013-0566-2.

30. Pan J, Gornall RJ, Ohba H. Saxifraga. In: Wu C, Raven PH, editors. Flora of China: Brassicaceae through Saxifragaceae. St. Louis: Science Press; Missouri Botanical Garden Press; 2001. p. 280-344.

31. Ebersbach J, Muellner-Riehl AN, Michalak I, Tkach N, Hoffmann MH, Röser M, et al. In and out of the Qinghai-Tibet Plateau: divergence time estimation and historical biogeography of the large arctic-alpine genus Saxifraga L. J Biogeogr. 2017;44:900-10. doi:10.1111/jbi.12899.

32. Gao Q, Li Y, Gornall RJ, Zhang Z, Zhang F, Xing R, et al. Phylogeny and speciation in Saxifraga sect. Ciliatae (Saxifragaceae): Evidence from psbAtrnH, trnL-F and ITS sequences. Taxon. 2015;64:703-13. doi:10.12705/644.3.

33. Gornall RJ. An outline of a revised classification of Saxifraga L. Bot J Linn Soc. 1987:273-92.

34. Beaulieu JM, Donoghue MJ. Fruit evolution and diversification in campanulid angiosperms. Evolution. 2013;67:3132-44. doi:10.1111/evo.12180.

35. Beaulieu JM, O'Meara BC. Extinction can be estimated from moderately sized molecular phylogenies. Evolution. 2015;69:1036-43. doi:10.1111/evo.12614

36. Mitchell JS, Rabosky DL. Bayesian model selection with BAMM: effects of the model prior on the inferred number of diversification shifts. Methods Ecol Evol. 2017:8:37-46.

37. Favre A, Michalak I, Chen C, Wang J, Pringle JS, Matuszak S, et al. Out-ofTibet: The spatio-temporal evolution of Gentiana (Gentianaceae). J Biogeogr. 2016. doi:10.1111/jbi.12840.

38. Jabbour F, Renner SS. A phylogeny of Delphinieae (Ranunculaceae) shows that Aconitum is nested within Delphinium and that Late Miocene transitions to long life cycles in the Himalayas and Southwest China coincide with bursts in diversification. Mol Phylogenet Evol. 2012;62:928-42. doi:10.1016/j.ympev.2011.12.005.

39. Drummond CS, Eastwood RJ, Miotto STS, Hughes CE. Multiple continental radiations and correlates of diversification in Lupinus (Leguminosae): Testing for key innovation with incomplete taxon sampling. Syst Biol. 2012;61:44360. doi:10.1093/sysbio/syr126.

40. von Hagen KB, Kadereit JW. The phylogeny of Gentianella (Gentianaceae) and its colonization of the southern hemisphere as revealed by nuclear and chloroplast DNA sequence variation. Org Divers Evol. 2001;1:61-79. doi:10. 1078/1439-6092-00005

41. Rabosky DL. Extinction rates should not be estimated from molecular phylogenies. Evolution. 2010;64:1816-24. doi:10.1111/j.1558-5646.2009.00926.x.

42. Nee S, Holmes EC, May RM, Harvey PH. Extinction rates can be estimated from molecular phylogenies. Philos Trans R Soc Lond Ser B Biol Sci. 1994; 344:77-82. doi:10.1098/rstb.1994.0054.

43. Silvestro D, Schnitzler J, Zizka G. A Bayesian framework to estimate diversification rates and their variation through time and space. BMC Evol Biol. 2011;11:311. doi:10.1186/1471-2148-11-311.

44. Xu B, Li Z, Sun H. Seed plants of the alpine subnival belt from the Hengduan Mountains. Southwest China: Science Press; 2014.

45. Lippert PC, van Hinsbergen DJ, Dupont-Nivet G. Early Cretaceous to present latitude of the central proto-Tibetan Plateau: A paleomagnetic synthesis with implications for Cenozoic tectonics, paleogeography, and climate of Asia. In: Nie J, Horton BK, Hoke GD, editors. Toward an Improved Understanding of Uplift Mechanisms and the Elevation History of the Tibetan Plateau. Boulder: Geological Society of America; 2014. p. 1-22. doi:10.1130/2014.2507(01).

46. Wang P, Scherler D, Liu-Zeng J, Mey J, Avouac J, Zhang Y, et al. Tectonic control of Yarlung Tsangpo Gorge revealed by a buried canyon in Southern Tibet. Science. 2014;346:978-81. doi:10.1126/science.1259041.

47. Sun B, Wu J, Liu Y, Ding S, Li X, Xie S, et al. Reconstructing Neogene vegetation and climates to infer tectonic uplift in western Yunnan, China. Palaeogeogr Palaeoclimatol Palaeoecol. 2011;304:328-36. doi:10.1016/j. palaeo.2010.09.023.
48. Xing $Y$, Ree RH. Uplift-driven diversification in the Hengduan Mountains, a temperate biodiversity hotspot. Proc Natl Acad Sci U S A. 2017; doi:10.1073/ pnas.1616063114.

49. Mosbrugger V, Favre A, Muellner-Riehl AN, Päckert M, Mulch A. Cenozoic Evolution of Geo-Biodiversity in the Tibeto-Himalayan Region. In: Mountains, Climate, and Biodiversity.

50. Zachos JC, Dickens GR, Zeebe RE. An early Cenozoic perspective on greenhouse warming and carbon-cycle dynamics. Nature. 2008;451:279-83. doi:10.1038/nature06588.

51. Zachos JC, Pagani M, Sloan L, Thomas E, Billups K. Trends, rhythms, and aberrations in global climate 65 Ma to present. Science. 2001;292:686-93. doi:10.1126/science.1059412.

52. Tank DC, Eastman JM, Pennell MW, Soltis PS, Soltis DE, Hinchliff CE, et al. Nested radiations and the pulse of angiosperm diversification: increased diversification rates often follow whole genome duplications. New Phytol. 2015;207:454-67. doi:10.1111/nph.13491.

53. Nie Z, Wen J, Gu Z, Boufford DE, Sun H. Polyploidy in the flora of the Hengduan Mountains Hotspot, Southwestern China. Ann Mo Bot Gard. 2005;92:275-306.

54. Zhang F, Li Y, Gao Q, Lei S, Khan G, Yang H, Chen S. Development and characterization of polymorphic microsatellite loci for Saxifraga egregia (Saxifragaceae). Appl Plant Sci. 2015. doi: 10.3732/apps.1500037.

55. Rubio de Casas R, Mort ME, Soltis DE. The influence of habitat on the evolution of plants: a case study across Saxifragales. Ann Bot. 2016. doi: 10. 1093/aob/mcw160.

56. Bürgel J. Hybridisation in Saxifraga subsection Kabschia (Saxifragaceae) from the Central Himalaya. Phyton. 2007;47:191-204.

57. Boucher FC, Lavergne S, Basile M, Choler P, Aubert S. Evolution and biogeography of the cushion life form in angiosperms. Perspect Plant Ecol Evol Syst. 2016;20:22-31. doi:10.1016/j.ppees.2016.03.002.

58. Roquet C, Boucher FC, Thuiller W, Lavergne S. Replicated radiations of the alpine genus Androsace (Primulaceae) driven by range expansion and convergent key innovations. J Biogeogr. 2013;40:1874-86. doi:10.1111/jbi.12135.

59. Donoghue MJ. Key innovations, convergence, and success: macroevolutionary lessons from plant phylogeny. Paleobiology. 2005;2:77-93.

60. Webb DA, Gornall RJ. A Manual of Saxifrages and their cultivation. 1st ed. Portland: Timber Press, Incorporated; 1989

61. Conti E, Soltis DE, Hardig TM, Schneider J. Phylogenetic relationships of the silver saxifrages (Saxifraga, sect. Ligulatae Haworth): implications for the evolution of substrate specificity, life histories, and biogeography. Mol Phylogenet Evol. 1999;13:536-55. doi: 10.1006/mpev.1999.0673

62. Spriggs EL, Clement WL, Sweeney PW, Madrinan S, Edwards EJ, Donoghue MJ. Temperate radiations and dying embers of a tropical past: the diversification of Viburnum. New Phytol. 2015;207:340-54. doi:10.1111/nph.13305.

63. Bouchenak-Khelladi $Y$, Onstein RE, Xing Y, Schwery O, Linder HP. On the complexity of triggering evolutionary radiations. New Phytol. 2015;207:31326. doi:10.1111/nph.13331.

64. Revell LJ. phytools: An R package for phylogenetic comparative biology (and other things). Methods Ecol Evol. 2012;3:217-23. doi:10.1111/j.2041210X.2011.00169.x

65. R Core Team. R: A Language and Environment for Statistical. Vienna, R Foundation for Statistical Computing; 2016.

66. Drummond AJ, Suchard MA, Xie D, Rambaut A. Bayesian phylogenetics with BEAUti and the BEAST 1.7. Mol Biol Evol. 2012;29:1969-73. doi:10.1093/ molbev/mss075.

67. Rabosky DL. Automatic detection of key innovations, rate shifts, and diversity-dependence on phylogenetic trees. PLoS One. 2014;9:e89543. doi: 10.1371/journal.pone.0089543.

68. Rabosky DL, Grundler M, Anderson C, Title P, Shi JJ, BROWN JW, et al. BAMMtools: An R package for the analysis of evolutionary dynamics on phylogenetic trees. Methods Ecol Evol. 2014:5:701-7. doi:10.1111/2041-210X.12199.

69. Rabosky DL, Santini F, Eastman J, Smith SA, Sidlauskas B, Chang J, et al. Rates of speciation and morphological evolution are correlated across the largest vertebrate radiation. Nat Commun. 2013:4:1958. doi:10.1038/ncomms2958.

70. DeChaine EG, Anderson SA, McNew JM, Wendling BM. On the evolutionary and biogeographic history of Saxifraga sect. Trachyphyllum (Gaud.) Koch (Saxifragaceae Juss.). PLoS One. 2013;8:e69814. doi:10.1371/journal.pone. 0069814

71. Zhang Z, Chen S, Gornall RJ. Morphology and anatomy of the exine in Saxifraga (Saxifragaceae). Phytotaxa. 2015;212:105. doi:10.11646/phytotaxa. 212.2.1. 
72. Moore BR, Hohna S, May MR, Rannala B, Huelsenbeck JP. Critically evaluating the theory and performance of Bayesian analysis of macroevolutionary mixtures. Proc Natl Acad Sci U S A. 2016;113:9569-74. doi:10.1073/pnas.1518659113.

73. Rabosky DL, Mitchell JS, Chang J. Is BAMM flawed? Theoretical and practical concerns in the analysis of multi-rate diversification models. Syst Biol. 2017. doi:10.1093/sysbio/syx037.

74. Kass RE, Raftery AE. Bayes Factors. J Am Stat Assoc. 1995;90:773-95. doi:10. 1080/01621459.1995.10476572.

75. Brouillet L, Elvander PE. Saxifraga. In: Flora of North America Editorial Committee, editor. Flora of North America; 2009. p. 43-166.

76. Akiyama S, Gornall RJ. Saxifraga. In: Watson A, et al., editors. Flora of Nepal; 2012. p. 254-303.

77. Horný R, Webr KM, Byam-Grounds J. Porophyllum saxifrages. Stamford: Byam-Grounds Publications; 1986

78. Fitzlohn RG. Diversitree: Comparative phylogenetic analyses of diversification in R. Methods Ecol Evol. 2012;3:1084-92. doi:10.1111/j.2041-210X.2012.00234.x.

79. Burin G, Kissling WD, Guimaraes PR Jr, Sekercioglu CH, Quental TB. Omnivory in birds is a macroevolutionary sink. Nat Commun. 2016;7:11250. doi:10.1038/ncomms 11250

80. Maddison WP, Midford P, Otto SP. Estimating a binary character's effect on speciation and extinction. Syst Biol. 2007:56:701-10.

81. Maddison WP, FitzJohn RG. The unsolved challenge to phylogenetic correlation tests for categorical characters. Syst Biol. 2015;64:127-36. doi:10. 1093/sysbio/syu070.

82. Davis MP, Midford PE, Maddison W. Exploring power and parameter estimation of the BiSSE method for analyzing species diversification. BMC Evol Biol. 2013;13:38. doi:10.1186/1471-2148-13-38.

83. Rabosky DL, Goldberg EE. Model inadequacy and mistaken inferences of traitdependent speciation. Syst Biol. 2015;64:340-55. doi:10.1093/sysbio/syu131.

84. Goldberg EE, Lancaster LT, Ree RH. Phylogenetic inference of reciprocal effects between geographic range evolution and diversification. Syst Biol. 2011;60:451-65. doi:10.1093/sysbio/syr046.

85. Boufford DE. Biodiversity Hotspot: China's Hengduan Mountains. Arnoldia. 2014; $72: 24-35$

86. Akaike H. On the Likelihood of a Time Series Model. Underst Stat. 1978;27: 217. doi:10.2307/2988185

87. Engler H, Irmscher E. Saxifragaceae - Saxifraga. In: Engler H, editor. Das Pflanzenreich. Regni vegetabilis conspectus, vol. 1919. Leipzig: Engelmann; 1916. p. 449-709.

\section{Submit your next manuscript to BioMed Central and we will help you at every step:}

- We accept pre-submission inquiries

- Our selector tool helps you to find the most relevant journal

- We provide round the clock customer support

- Convenient online submission

- Thorough peer review

- Inclusion in PubMed and all major indexing services

- Maximum visibility for your research

Submit your manuscript at www.biomedcentral.com/submit
Biomed Central 